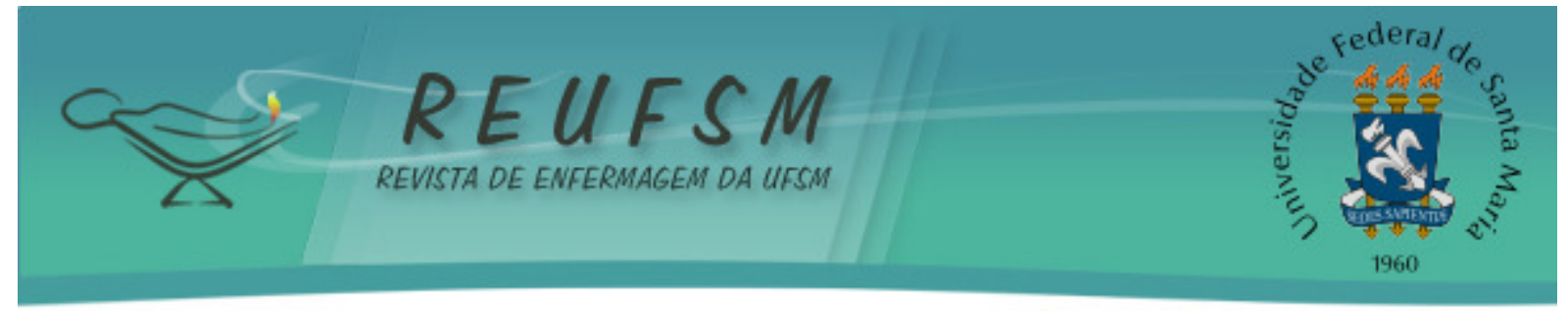

RELATO DE EXPERIÊNCIA

\title{
AÇÃO PEDAGÓGICA DA ENFERMAGEM NA ESCOLA: APRENDER, REFLETIR E AGIR NA PREVENÇÃO DA DENGUE
}

\section{PEDAGOGICAL ACTION OF NURSING AT SCHOOL: LEARNING, REFLECTING AND ACTING IN THE PREVENTION OF DENGUE}

\section{ACCIÓN PEDAGÓGICA DE LA ENFERMERÍA EN LA ESCUELA: APRENDER, REFLEXIONAR Y ACTUAR EN LA PREVENCIÓN DE LA DENGUE}

\author{
Fabiano Pereira dos Santos ${ }^{1}$ \\ Priscila da Silva Matter ${ }^{2}$ \\ Adriane Cristina Bernat Kolankiewicz ${ }^{3}$
}

Doi: $10.5902 / 2179769221947$

RESUMO: Objetivo: descrever a experiência de ação intersetorial na atenção básica com discentes de enfermagem. Método: relato de experiência, a partir do desenvolvimento de atividades na escola, com a participação de 153 estudantes, no mês de março de 2016. Resultados: os estudantes foram estimulados a desenvolver ações de controle e prevenção da disseminação do mosquito Aedes aegypti, por meio do pensamento intersetorial entre instituições alocadas em uma mesma comunidade, sob a luz do Programa Saúde na Escola. Considerações finais: o desenvolvimento de estratégias e alinhamentos de ações em conjunto na organização intersetorial promove intervenções convergentes para melhorias comunitárias. Desse modo, trabalhar interligado deflagra crescimento em saúde, sociedade e política, com intuito preventivo e de promoção em saúde de maneira inclusiva, discutida pelos diversos atores institucionais.

Descritores: Enfermagem em saúde pública; Dengue; Ação Intersetorial; Saúde escolar; Educação em saúde.

ABSTRACT: Aim: to describe the experience of intersectoral action in primary care with nursing students. Method: experience report, from the development of activities at school, with the participation of 153 students, in March 2016. Results: the students were stimulated to develop actions to control and prevent the dissemination of the Aedes Aegypti mosquito, by means of intersectoral thinking among institutions located in the same community, enlightened by the School Health Program. Final considerations: the development of conjoined strategies and alignments of actions in intersectoral organization promotes convergent interventions for community improvements. Accordingly, the intertwined work entails growth in health, society and politics, with preventive intent promotion of health in an inclusive way, discussed by several institutional actors.

Descriptors: Public health nursing; Dengue; Intersectoral action; School health; Health education.

\footnotetext{
${ }^{1}$ Enfermeiro. Mestrando do Programa de Pós-Graduação em Enfermagem na Universidade Federal de Santa Maria/UFSM. Santa Maria (RS), Brasil (BR). E-mail: santosfabiano210@gmail.com

${ }^{2}$ Enfermeira. Residente no Programa Residência Multiprofissional na Universidade Regional do Noroeste do Estado do Rio Grande do Sul/UNIJUÍ. Santa Rosa (RS), Brasil (BR). E-mail: prymatter@ hotmail.com

${ }^{3}$ Enfermeira. Doutora em Ciências. Docente de Graduação em Enfermagem e do Programa de Pós-Graduação em Atenção Integral à Saúde na Universidade Regional do Noroeste do Estado do Rio Grande do Sul/UNIJUÍ. Ijuí (RS), Brasil (BR). E-mail: adri.saudecoletiva@gmail.com
} 


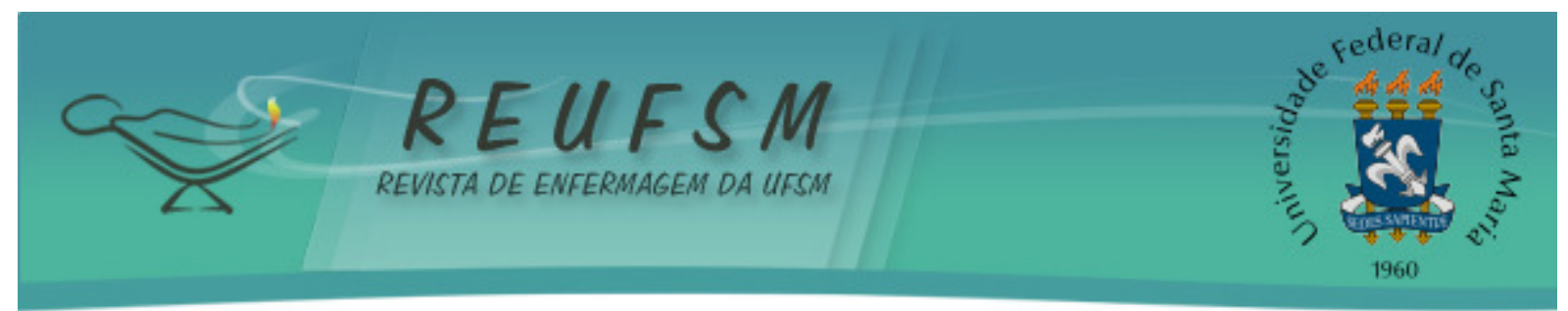

RESUMEN: Objetivo: describir la experiencia de acción intersectorial en la atención primaria con estudiantes de enfermería. Método: relato de experiencia, a partir de las actividades desarrolladas en una escuela, con la participación de 153 estudiantes, en marzo de 2016. Resultados: los estudiantes fueron estimulados a desarrollar acciones de control y prevención de la diseminación del mosquito Aedes Aegypti, por medio del pensamiento intersectorial entre instituciones ubicadas en la misma comunidad, a partir del Programa de Salud Escolar. Consideraciones finales: el desarrollo de estrategias y alineamiento de acciones en conjunto en la organización intersectorial promueve intervenciones convergentes para mejoramientos comunitarios. De ese modo, trabajar interconectado implica crecimiento en salud, sociedad y política, con el objetivo preventivo y de promoción en salud de manera inclusiva, discutida por los diversos actores institucionales.

Descriptores: Enfermería en salud pública; Dengue; Acción intersectorial; Salud escolar; Educación para la salud.

\section{INTRODUÇÃO}

A equipe da Estratégia de Saúde da Família (ESF), implantada em meados de 1990, no Brasil, é a principal provedora de cuidados na Atenção Básica (AB) aos usuários adstritos ao seu território, por meio do trabalho de uma equipe composta por médico, enfermeiro, técnicos de enfermagem e agentes comunitários da saúde. ${ }^{1}$

A equipe que atua neste território adstrito deve observar e identificar as necessidades dos usuários, a fim de contribuir com esta população. A comunicação é uma das tecnologias empregadas, a qual poderá contribuir na construção do vínculo entre profissionais de saúde e usuários. $^{2} \mathrm{O}$ conjunto de ações desenvolvidas na $\mathrm{AB}$, desde ações de promoção, prevenção e reabilitação, auxiliam na avaliação e identificação das possíveis intervenções, com o intuito de promover mudanças, a partir de uma reflexão crítica que conduza a boas práticas de saúde. ${ }^{3}$

Uma das ações que pode ser identificada como necessidade no território, é o envolvimento dos profissionais de saúde e educação no Programa Saúde na Escola (PSE). O PSE é um programa focado na promoção e prevenção da saúde de crianças, adolescentes e jovens em idade escolar. ${ }^{4}$ Desse modo, contribui para que a saúde possa ser pensada, discutida e ampliada na comunidade.

Os temas transversais trabalhados em consonância com atividades didáticas na escola contribuem para a aprendizagem escolar. É nesse contexto que o tema dengue pode ser abordado com os estudantes para esclarecimentos sobre a doença, sinais e sintomas, meios de transmissão, criadouros e combate ao mosquito vetor. ${ }^{5}$ Esse modelo educativo em saúde respeita a realidade cultural e pessoal do corpo discente e docente da escola, bem como dos 


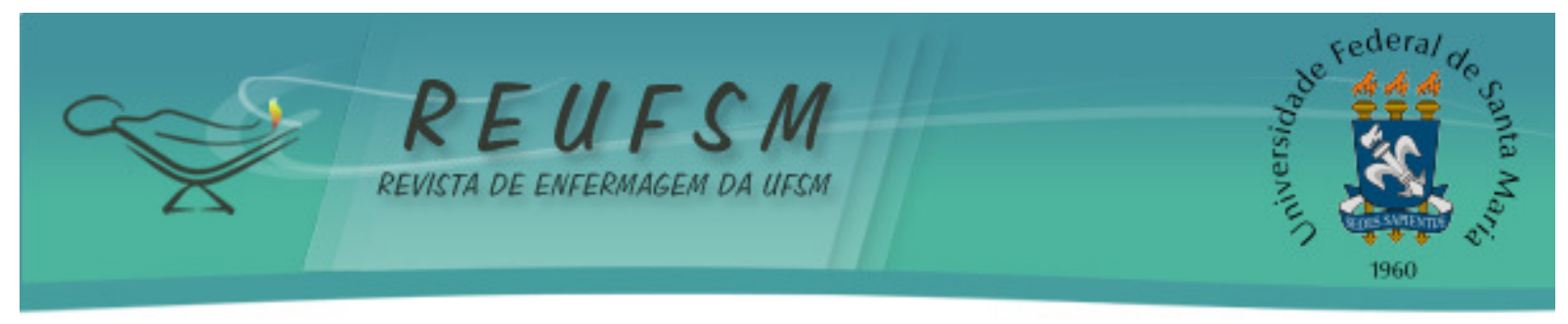

profissionais da ESF; possibilita a construção do conhecimento pautado em evidências, práticas no combate ao mosquito da dengue e o empoderamento através do saber em saúde. ${ }^{6}$

Ações intersetoriais são desenvolvidas, por meio do envolvimento de pessoas de outros setores ou associações, com finalidade de potencializar práticas convergentes à saúde comunitária e, desta maneira, contribuir para o cuidado integral da população, concretizando a rede de apoio. ${ }^{7}$

A partir deste contexto, este artigo teve por objetivo descrever a experiência de ação intersetorial na atenção básica com discentes de enfermagem.

\section{MÉTODO}

Trata-se de um estudo do tipo relato de experiência, baseado em atividades educativas sobre a dengue, realizadas junto à comunidade escolar, voltadas para a promoção, prevenção e educação em saúde. As ações foram desenvolvidas por três acadêmicos do nono semestre do curso de Enfermagem da Universidade Regional do Noroeste do Estado do Rio Grande do Sul (UNIJUÍ), durante o Estágio Curricular Supervisionado em Enfermagem (ECSE I), com um total de 210 horas, sob supervisão de um docente enfermeiro da universidade e com a participação do enfermeiro da ESF. O território da unidade de saúde tem população aproximada de 4.000 habitantes e conta com as seguintes instituições: escolas, creches, igrejas, indústrias, empresas de pequeno porte e associação de moradores.

Primeiramente realizou-se uma visita na escola para averiguar as necessidades pedagógicas em torno de temas transversais para a realização de atividades com os estudantes. Durante esse encontro foi expressa pela equipe diretiva da escola a necessidade de trabalhar doenças emergentes como a Dengue clássica e hemorrágica, seus sinais e sintomas e o combate ao mosquito Aedes aegypti.

Após agendamento prévio na escola, que contempla 243 estudantes matriculados, as atividades foram planejadas e, posteriormente, desenvolvidas em turmas dos turnos da manhã e tarde, separadas de acordo com o grau de estudo dos alunos, sendo eles do pré-escolar ao nono ano, totalizando 153 estudantes, e com 10 horas trabalhadas. A prática foi realizada durante o mês de março de 2016, em uma escola estadual de ensino fundamental do Município de Ijuí, no Rio Grande do Sul.

Os 153 estudantes foram distribuídos do pré-escolar até o nono ano, da seguinte forma: 11 alunos do pré-escolar, sete do primeiro ano, sete do segundo ano, 11 do terceiro 


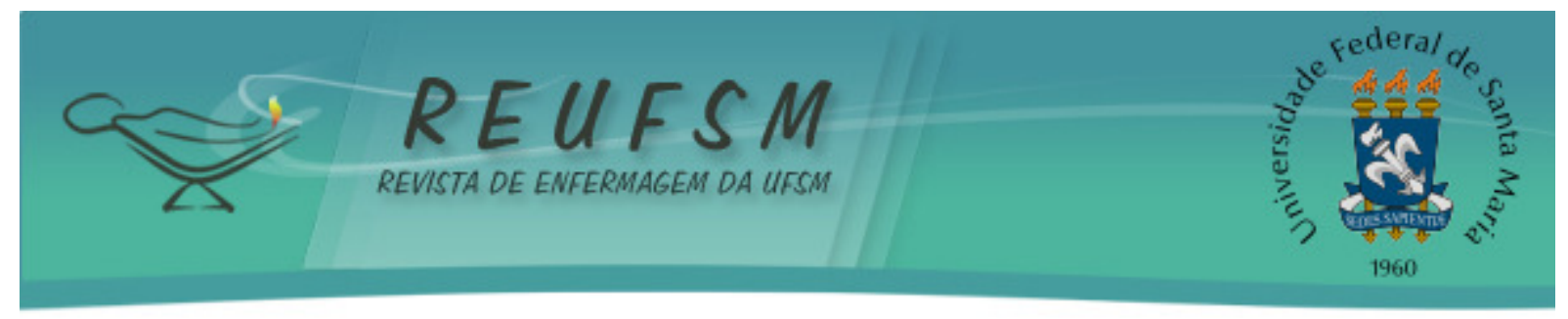

ano, 12 do terceiro ano, 16 do quarto ano, 18 do quinto ano, 23 do sexto ano, 27 do sétimo ano, 11 do oitavo ano e 10 do nono ano. Para a realização das atividades foram agrupadas as turmas de acordo com a seriação escolar.

Com os estudantes do quarto ao nono ano, os temas foram elucidados através de gincana educativa, na qual foram instigados a trabalhar em equipe, refletir, discutir e responder as questões colocadas como afirmativas sobre as doenças emergentes. Os alunos do pré-escolar ao terceiro ano realizaram atividades de recorte, pintura, vídeos educativos, música e uma busca por potenciais criadouros de mosquito Aedes aegypti no pátio da escola, onde tiveram a oportunidade de aprender sobre o mosquito, a doença, seus sintomas e formas de prevenção.

A partir dessa organização, realizou-se o desenvolvimento de atividades, que foram divididas em vários momentos. Foi utilizado um período de 60 minutos para cada grupo desenvolver seu aprendizado e discussão sobre dengue e suas consequências no organismo humano. O agrupamento ocorreu da seguinte forma: grupo 1 - pré-escolar, grupo 2 - primeiro, segundo e terceiro anos, grupo 3 - quarto e quinto anos, grupo 4 - sexto e sétimo anos e grupo 5 - oitavo e nono anos. O tempo utilizado foi de cinco horas, acrescido de cinco horas para planejamento e construção de material didático.

O planejamento das atividades teve como foco a intervenção de acordo com a Metodologia Problematizadora (MP), a qual tem em suas premissas o levantamento do problema, teorização, levantamento de hipóteses de solução e aplicação na realidade. ${ }^{8}$

\section{RESULTADOS E DISCUSSÃO}

As atividades realizadas com os estudantes envolveram trabalhos lúdicos, com o desenvolvimento da motricidade grossa e fina nas séries iniciais, por meio da pintura de máscara do mosquito da dengue, recorte e colagem no palito de picolé, dança, identificação de materiais e movimento de pinça na coleta de potenciais criadouros do mosquito no pátio da escola.

Com os estudantes do quarto ao nono ano foi realizada gincana com jogo do mito e verdade, no qual para cada equipe foram dispostas placas com a cor verde para verdade e vermelha para mito. Desse modo, a cada afirmativa exposta em meio eletrônico projetado em parede com fundo branco, era exposta uma frase afirmativa sobre o assunto dengue e com tempo determinado para escolha da opção que a equipe considerava correta. $\mathrm{O}$ caça-palavra 


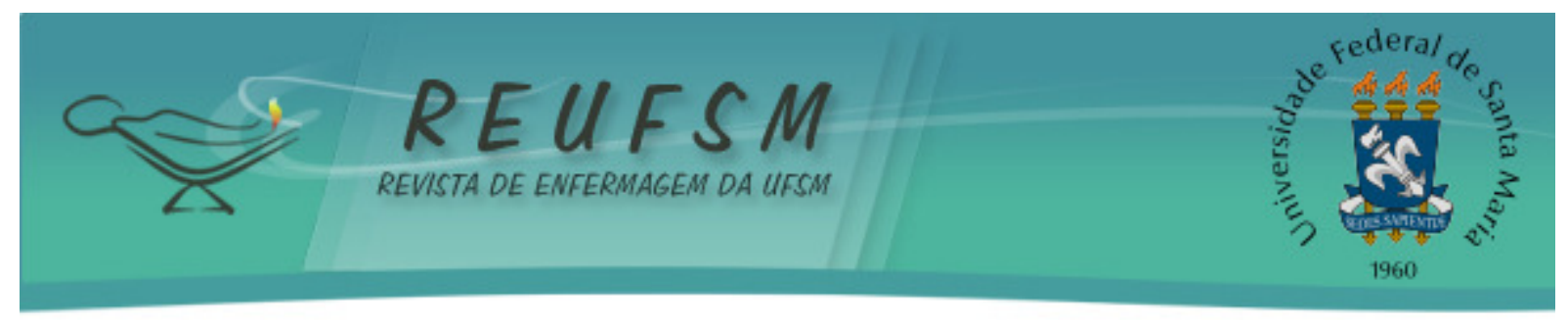

foi introduzido no decorrer da atividade do mito e verdade, com a finalidade de verificar o grau de abstração e memorização do assunto por parte dos estudantes.

Com essas intervenções precoces em educação em saúde desenvolvidas no período da construção da linguagem oral e escrita, pressupõe-se a objetivação prática no pensamento preventivo, composto por desafios convergentes entre a educação e saúde. ${ }^{9}$ Ocorre com esse ato de instigação a construção, no contexto educacional, das habilidades cognitivas relacionadas ao aprendizado gradativo e constante.

Com o desenvolvimento da MP, identificou-se como problema a falta de interação entre ESF e escola no desenvolvimento de atividades voltadas a questões emergentes, como a alta incidência de casos de dengue no munícipio. Em seguida, realizaram-se a teorização e a busca de atividades lúdicas para o agir pedagógico na escola. Com o levantamento de problemas e posterior teorização sobre dengue, a aplicação prática realizada na realidade foi ao encontro das prioridades da população no combate e controle do mosquito vetor da dengue.

Portanto é fundamental, para o futuro enfermeiro, a constituição de elementos caracterizadores de promoção e prevenção direcionados para a criação de protocolos de atendimento e desenvolvimento de ações sociais na comunidade. ${ }^{10}$

$\mathrm{Na}$ atualidade, pensar de forma interdisciplinar e interinstitucional é uma ponte para o desenvolvimento de novas tecnologias capazes de agregar valores com o foco no sujeito humano. Para construir esse pensamento, é necessária a construção pelos profissionais de uma nova forma de encarar a realidade, a partir da desconstrução dos antigos pressupostos e da reconstrução de novos valores pessoais e interpessoais, ${ }^{11}$ voltados para a promoção tanto de saúde, como da educação de forma crítica e formadora de cidadãos capacitados para um olhar integral e preventivo sobre sua própria realidade. ${ }^{12}$

Este pensar de forma diferente remete à interligação da escola e da ESF na tratativa de temas sobre doenças emergentes. A dengue é um tema importante na formação dos estudantes nas escolas porque, como fio condutor, foram criadas políticas de integração preconizadas entre o Sistema Único de Saúde (SUS) e a educação. ${ }^{13}$ Orienta, dessa forma, para uma educação voltada para o saber integral e social.

O avanço e o aumento de casos de dengue no Brasil vêm ocorrendo de forma acelerada em todas as regiões. A dengue é transmitida pela picada do mosquito do gênero Aedes infectado e circula com quatro sorotipos, os sorotipos do vírus da Dengue tipo 1, 


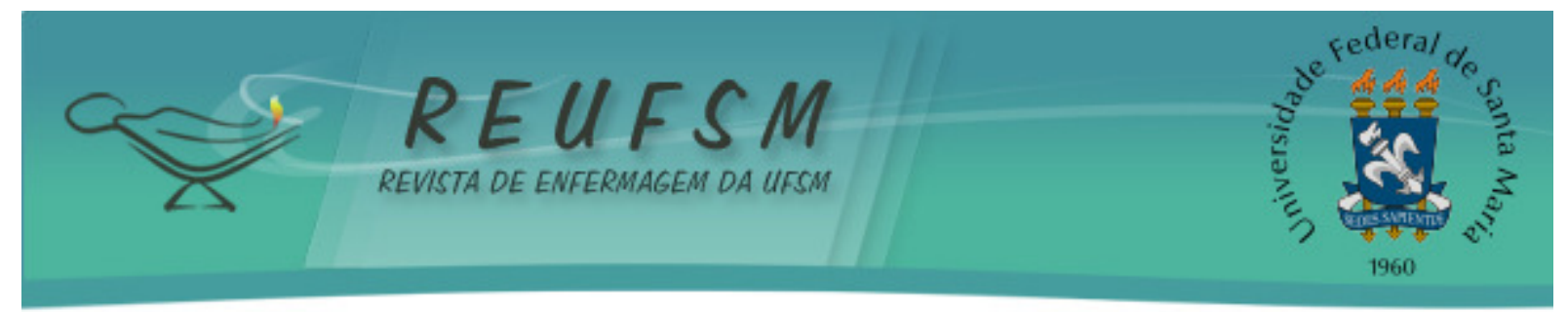

Dengue tipo 2, Dengue tipo 3 e Dengue tipo $4,{ }^{14}$ e, nas últimas três décadas, sua incidência é constatada em mais de cento e vinte e cinco países.

A urbanização, as mudanças econômicas, a exploração extrativa, os hábitos, as políticas e os comportamentos da sociedade brasileira são fatores definidos como fundamentais para o avanço do mosquito Aedes aegypti sobre as cidades. ${ }^{15}$

A educação em saúde entre os muros da escola requer das pessoas que atuam nessa área o conhecimento aprofundado sobre a temática, porque esse ato educativo terá a construção do conhecimento em saúde voltado para a prática social do bem-estar, como forma de prevenção de futuros agravos à saúde. ${ }^{16}$ Portanto, a ESF tem a responsabilidade de orientar, construir juntamente com a escola e a sociedade civil, novos modelos de educação em saúde voltados para o entendimento claro e com consciência preventiva. ${ }^{17}$

Buscou-se a ludicidade como forma de trocar conhecimento com os estudantes, a partir de sua seriação, construindo a educação em saúde voltada para o desenvolvimento das várias dimensões humanas, como cognição, motricidade e afetividade, apoiadas na troca de conhecimentos. ${ }^{18}$ Com os alunos do pré-escolar ao terceiro ano, foram realizados a visualização de vídeos educativos, desenhos para colorir, confecção de máscara do mosquito, uma breve discussão sobre sinais e sintomas, as formas com que o mosquito pode se reproduzir no meio ambiente e a importância do cuidado com a água parada e seus meios de acúmulo.

No meio externo da escola foram realizadas pelos alunos a identificação e coleta de materiais que podem acumular água e se tornarem potenciais criadouros do mosquito Aedes aegypti. Todos tiveram oportunidade de participar e de falar um pouco sobre a dengue, alguns se mostraram mais preocupados com o mosquito, outros com a doença, mas a maioria demonstrou empoderamento sobre o assunto, boa aceitação e comprometimento.

Já, com as turmas do quarto ao nono anos foi trabalhado o tema por meio de gincana, no qual duas equipes competiam ao analisarem se as afirmações repassadas se tratavam de mitos ou verdades. Desta forma, foi possível prender a atenção dos estudantes, trazê-los para a discussão e transmitir as informações, já que as respostas verdadeiras posteriormente eram reveladas, discutidas e esclarecidas. 


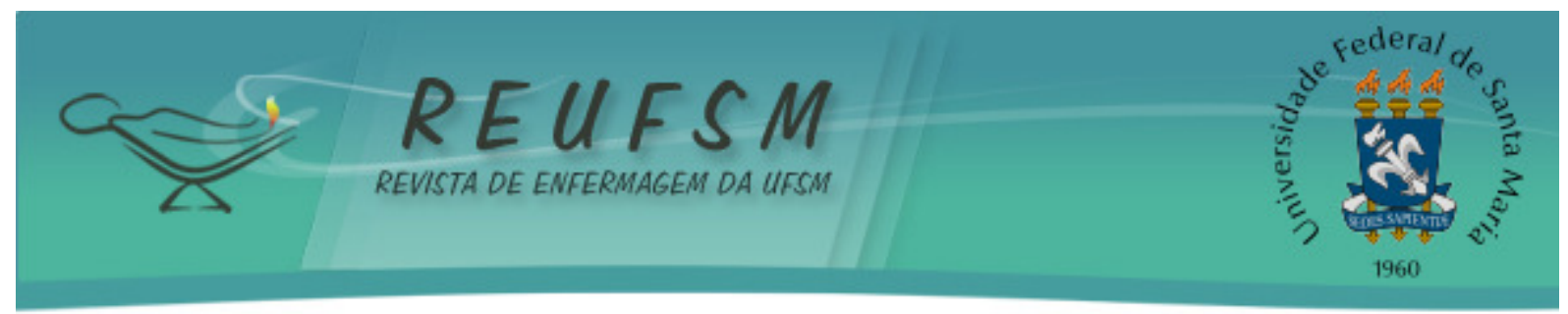

O uso de jogos facilitou a discussão sobre a dengue e estas intervenções agregaram valores humanos pois, por meio de jogos e atividades lúdicas, é possível conscientizar e criar vínculos com os alunos, de modo a construir pensamentos críticos. ${ }^{18}$

A inserção dos estudantes é fundamental para a construção da cidadania social e de um olhar integral sobre os problemas encontrados na sociedade. Também é importante para a formação dos futuros enfermeiros intervir na realidade por meio da metodologia da problematização, ${ }^{8}$ e construir o pensamento cognitivo, aprender a aprender, através dos seus conhecimentos prévios sobre a temática proposta para as atividades na escola. ${ }^{19}$

Atividades a partir de jogos teatrais foram desenvolvidas no Município de Itaboraí, no Estado do Rio de Janeiro, com intenção de ampliar a visão sobre a prevenção da dengue. Utilizaram-se como metodologia a arte e o teatro para promover e desenvolver o aprendizado apoiado na participação escolar. ${ }^{20}$ Aponta-se que essa inclusão se associa com este relato de experiência, demonstrando que a equipe de saúde deve ter presença consolidada nas diversas instituições sociais.

No Estado do Amazonas, no Município de Itacoatiara foram realizados estudos e aplicação da webconferência com estudantes de ensino básico. Nesse estudo ficou evidenciada a importância da utilização da teleconferência para esclarecimentos sobre o controle e combate ao mosquito transmissor da dengue, porque nesse estado existem inúmeras localidades distantes. ${ }^{21}$

A discussão sobre a atividade aconteceu em sala de aula, com intuito de avaliar a atividade e compartilhar com outros estudantes a experiência na escola. Importante destacar que é necessário avaliar a atividade, de modo a aprimorar as dinâmicas e didáticas aplicadas na realidade escolar.

Dessa forma, conhecer a comunidade é um dos princípios da política do SUS, que prevê o cuidado integral e ampliado para todas as pessoas adscritas na ESF. A partir disso, espera-se de todos a construção do conhecimento para a conscientização sobre as doenças emergentes, seus sinais e sintomas e formas de combate para a não proliferação do vetor dessas doenças. Assim se contribui para a formação cidadã, social e política dos estudantes, equipe de professores, equipe diretiva e os próprios acadêmicos. 


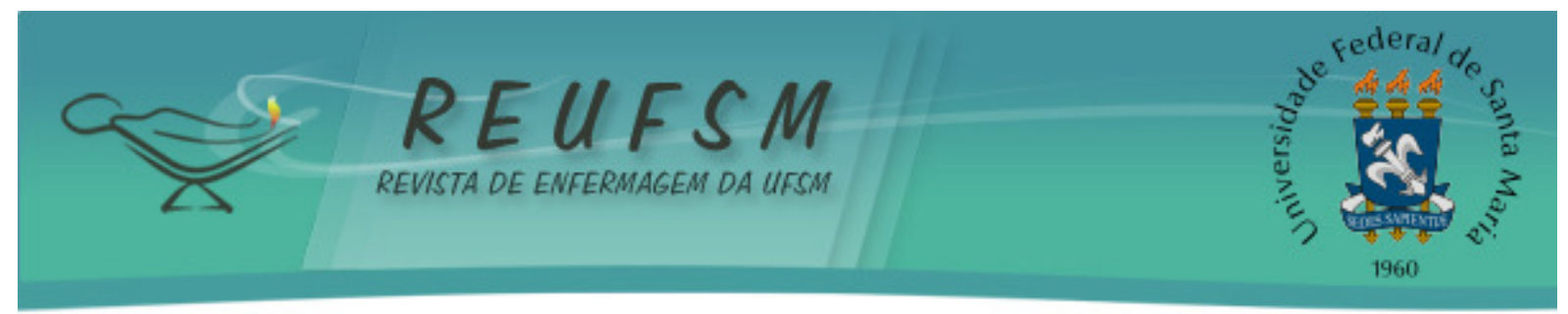

\section{CONSIDERAÇÕES FINAIS}

Este relato de experiência teve a finalidade descrever a experiência vivenciada pelos estudantes de enfermagem inseridos no contexto de combate e controle da expansão do mosquito Aedes aegypti. As atividades foram realizadas de forma lúdica, com método didático para ajudar na construção da conscientização dos estudantes, professores, equipe de saúde, equipe diretiva e futuros enfermeiros.

A reflexão crítica em torno do serviço feito de modo cooperativo demonstrou, através deste relato de experiência, que é fundamental a construção de redes e laços entre as instituições alocadas na mesma região, demonstrando que o trabalho, quando instituído através de ações planejadas e estruturadas de forma clara e objetivas, é capaz de transformar a realidade da comunidade e também contribui para o esclarecimento social apoiado na educação em saúde.

Uma das limitações do estudo é que o relato se deu a partir de uma experiência a nível local. Entretanto, pode ser replicada em novas unidades de Estratégia de Saúde da Família e escolas, com uma maior participação dos estudantes.

\section{REFERENCIAS}

1. Pimentel FC, Albuquerque PC, Souza WV. A estratégia saúde da família no estado de Pernambuco: avaliação da estrutura das equipes por porte populacional. Saúde debate [Internet]. 2015 [acesso em 2016 maio 12];39(104):88-101. Disponível em: http://www.scielo.br/pdf/sdeb/v39n104/0103-1104-sdeb-39-104-00088.pdf.

2. Kolankiewicz ACB, Loro MM, Magnago TSBS, Rosanelli CLSP, Domenico EBLD. Demandas de cuidado de pacientes oncológicos: proposta de intervenção pela convergência e prática educativa. Rev Enferm UFPE [Internet]. 2015 [acesso em 2016 maio 12];9(12):1370-5. Disponível em: http://www.revista.ufpe.br/revistaenfermagem/index.php/revista/article/view/8612/pdf_9151.

3. Padilla B, Hernández-Plaza S, Ortiz A. Avaliando as boas práticas em saúde e migrações em Portugal: teoria, prática e política. Forum Sociológico [Internet]. 2012 [acesso em 2016 maio 12];22:33-41. Disponível em: http://sociologico.revues.org/550.

4. Brasil. Ministério da Saúde. Ministério da Educação. Decreto $n^{\circ}$ 6.286, de 05 de dezembro de 2007. Institui o Programa Saúde na Escola - PSE, e dá outras providências. [Internet]. 2007 [acesso em 2016 abr 08]. Disponível em: http://www.planalto.gov.br/ccivil_03/_ato2007-2010/2007/decreto/d6286.htm.

5. Pastoriza TB, Silva EN. O ensino interdisciplinar do tema dengue: uma proposta para a geografia. Hygeia [Internet]. 2014 jun [acesso em 2016 abr 02];10(18):71-1. Disponível em: http://www.seer.ufu.br/index.php/hygeia/article/view/23341.

6. Almeida ER, Moutinho CB, Leite MTS. Prática pedagógica de enfermeiros de saúde da família no desenvolvimento da educação em saúde. Inferface Comum Saúde Educ [Internet]. 


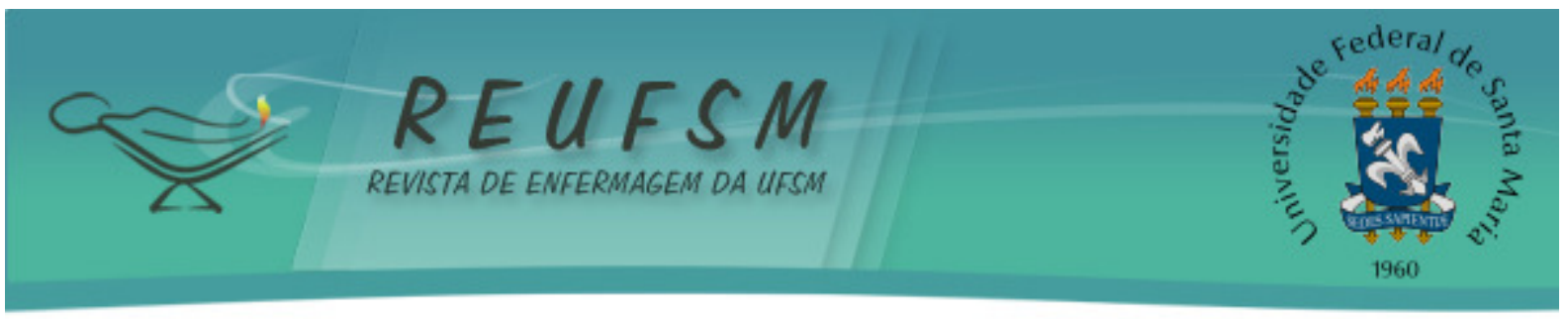

2016 [acesso em 2016 maio 15];20(57):389-01. Disponível em: http://www.scielo.br/pdf/icse/2016nahead/1807-5762-icse-1807-576220150128.pdf.

7. Azevedo E, Pelicioni MCF, Westphal MF. Práticas intersetoriais nas políticas públicas de promoção de saúde. Physis (Rio J) [Internet]. 2012 [acesso em 2016 nov 22];22(4):1333-56. Disponível em: http://www.scielo.br/pdf/physis/v22n4/a05v22n4.pdf.

8. Berbel NAN. Metodologia da problematização: respostas de lições extraídas da prática. Semina Cien Soc Hum [Internet]. 2014 [acesso em 2016 abr 08];35(2):61-7. Disponível em: http://www.uel.br/revistas/uel/index.php/seminasoc/article/view/18193/1650.

9. Ganz JS, Campos LM, Silva PB, Mecca TP, Almeida RP, Melo CRB, et al. Programa de estimulação cognitiva "ativamente" para o ensino infantil. Psicopedagogia [Internet]. 2015 [acesso em 2016 maio 15];32(97):14-25. Disponível em: http://pepsic.bvsalud.org/pdf/psicoped/v32n97/03.pdf.

10. Daher MJE, Barreto BTB, Carvalho SC. Dengue: aplicação do protocolo de atendimento pelos enfermeiros. Rev Enferm UFSM [Internet]. 2013 set-dez [acesso em 2016 abr 03];3(3):440-8. Disponível em: http://periodicos.ufsm.br/reufsm/article/view/9069/pdf.

11. Pereira RCA, Rivera FJU, Artmann E. O trabalho multiprofissional na estratégia saúde da família: estudo sobre modalidades de equipes. Interface Comum Saúde Educ [Internet]. 2013 abr-jun [acesso em 2016 abr 04];17(45):327-40. Disponível em: http://www.scielosp.org/pdf/icse/v17n45/aop0613.pdf.

12. Duarte MLC, Boeck JN. O trabalho em equipe na enfermagem e os limites e possibilidades da estratégia saúde da família. Trab Educ Saúde [Internet]. 2015 set-dez [acesso em 2016 abr 02];13(3):709-20. Disponível em: http://www.scielo.br/pdf/tes/v13n3/1981-7746-tes-13-03-0709.pdf.

13. Assis SS, Pimenta DN, Schall VT. Conhecimentos e práticas educativas sobre dengue: a perspectiva de professores e profissionais da saúde. Ens Pesqui Educ Cienc [Internet]. 2013 [acesso em 2016 abr 08];15(1):131-53. Disponível em: http://www.scielo.br/pdf/epec/v15n1/1983-2117-epec-15-01-00131.pdf.

14. Gonçalves RP, Lima EC, Lima JWO, Silva MGC, Caprara A. Contribuições recentes sobre conhecimentos, atitudes e práticas da população brasileira acerca da dengue. Saúde Soc [Internet]. 2015 [acesso em 2016 abr 03];24(2):578-93. Disponível em: http://www.scielo.br/pdf/sausoc/v24n2/0104-1290-sausoc-24-02-00578.pdf.

15. Brasil. Ministério da Saúde. Secretaria de Vigilância em Saúde. Vigilância em saúde: ações inovadoras e resultados - Gestão 2011-2014 [Internet]. Brasília; 2015 [acesso em 2016 abr 04]. Disponível em: http://u.saude.gov.br/images/pdf/2015/janeiro/22/relatorio-gestaosvs-2011-2014-preliminar.pdf.

16. Penso MA, Brasil KCTR, Arrais AR, Lordello SR. A relação entre saúde e escola: percepções dos profissionais que trabalham com adolescentes na atenção primária à saúde no Distrito Federal. Saúde Soc [Internet]. 2013 [acesso em 2016 abr 01];22(2):542-53. Disponível em: http://www.scielo.br/pdf/sausoc/v22n2/v22n2a23.pdf.

17. Köptcke LS, Caixeta IA, Rocha FG. O olhar de cada um: elementos sobre a construção cotidiana do programa saúde na escola no DF. Tempus Actas Saúde Colet [Internet]. 2015 set 


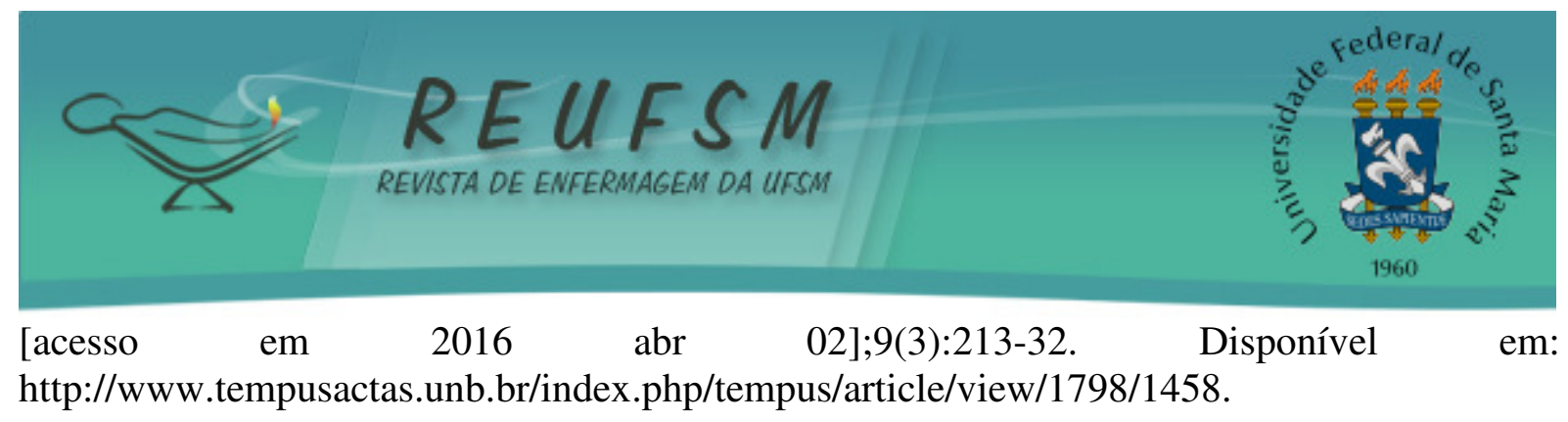

18. Almeida TJ, Salvador PTCO, Alves KYA, Sousa ICA. Playful education in health: report of an experience of "luminescent nurses". Rev Pesqui Cuid Fundam [Internet]. 2013 [acesso em 2016 abr 02];5(5):122-30. Disponível em: http://www.seer.unirio.br/index.php/cuidadofundamental/article/view/1642/pdf_1010.

19. Carvalho DPSRP, Rego ALC, Ferreira KS, Silva SB, Vitor AF, Junior MAF. Teoria da aprendizagem significativa como proposta para inovação no ensino de enfermagem: experiência dos estudantes. Rev Enferm UFSM [Internet]. 2015 jan-mar [acesso em 2016 abr 02];5(1):186-92. Disponível em: http://periodicos.ufsm.br/reufsm/article/view/13210/pdf.

20. Oliveira DF, Mendonça CCR, Meirelles RMS, Coutinho CMLM, Araújo-Jorge TC, Luz MRMP. Construção de espaços de escuta, diagnóstico e análise coletiva de problemas de saúde pública com a linguagem teatral: o caso das oficinas de jogos teatrais sobre a dengue. Interface Comum Saúde Educ [Internet]. 2012 out-dez [acesso em 2016 maio 15];16(43):92941. Disponível em: http://www.scielo.br/pdf/icse/2012nahead/aop5712.pdf.

21. Costa CA, Petrucio WS, Rodrigues PMA, Lages RO, Wen CL. Efetividade das práticas de teleducação por webconferência no combate à dengue no Estado do Amazonas, Brasil. J Health Inform [Internet]. 2014 jan-mar [acesso em 2016 maio 15];6(1):15-8. Disponível em: http://www.jhi-sbis.saude.ws/ojs-jhi/index.php/jhi-sbis/article/viewFile/272/192.

Data de recebimento: $23 / 11 / 2016$

Data de aceite: 19/06/2017

Autor principal: Adriane Cristina Bernat Kolankiewicz

Endereço Postal: Universidade Regional do Noroeste do Estado do Rio Grande do Sul/UNIJUÍ. Rua do Comércio n³000, Departamento de Ciências da Vida (DCVida), CEP: 98700-000, Ijuí/RS. E-mail: adri.saudecoletiva@gmail.com 